\title{
Palladium nanoparticle anchored polyphosphazene nanotubes: preparation and catalytic activity on aryl coupling reactions
}

\author{
V DEVI $^{1}$, A ASHOK KUMAR ${ }^{2}$, S SANKAR ${ }^{1}$ and K DINAKARAN ${ }^{3, *}$ \\ ${ }^{1}$ Department of Physics, MIT Campus, Anna University, Chennai 600 044, India \\ ${ }^{2}$ Department of Chemistry, APA College of Arts and Culture, Palani, Tamil Nadu 624 601, India \\ ${ }^{3}$ Department of Chemistry, Thiruvalluvar University, Vellore 632 115, India
}

MS received 2 December 2014; revised 2 February 2015

\begin{abstract}
Highly accessible-supported palladium (Pd) nanoparticles anchored polyphosphazene (PPZ) nanotubes (NTs) having average diameter of $120 \mathrm{~nm}$ were synthesized rapidly at room temperature and homogeneously decorated with Pd nanoparticles. The resultant PPZ-Pd nanocomposites were morphologically and structurally characterized by means of transmission electron microscope equipped with energy-dispersive X-ray spectroscopy and $\mathrm{X}$-ray diffraction analysis. Characterization results showed that the Pd nanoparticles with good dispersibility could be well anchored onto the surfaces of the PPZ NTs. The PPZ-Pd NTs show enhanced catalytic activity for the Suzuki coupling of aryl bromides with arylboronic acid. In addition, these PPZ-Pd NTs show excellent behaviour as reusable catalysts of the Suzuki and Heck coupling reactions.
\end{abstract}

Keywords. Polyphosphazene nanotubes; palladium nanoparticle; nanocatalyst; Suzuki coupling reaction; Heck coupling reaction.

\section{Introduction}

Organic aryl-aryl coupling reaction through palladium $(\mathrm{Pd})$ catalysed aryl-aryl coupling reactions have been attracting interest due to widespread synthetic application of organic molecules that are widely used for the synthesis of fine chemicals, pharmaceuticals, dyes as well as electro-catalyst in fuel cell. ${ }^{1-4}$ In general, the organic synthesis using Pd catalyst is carried out in organic solvents using homogeneous or heterogeneous Pd catalysts, in the presence of a variety of phosphine-based ligands. ${ }^{5,6}$ The remarkable structural variation of phosphine-based ligands, often induced by a subtle modification of the reaction conditions or the reagents employed, has been a major driving force for the sustained activity in this area. However, aggregation of catalyst often limits their applications. The problem of aggregation, catalyst recovery and pollution by phosphine ligands are the matter of concern, especially for the pharmaceutical industry. In addition, the large-scale applications on industrial and semiindustrial scale, the phosphines might be a more serious economical burden than even palladium $(\mathrm{Pd})$ itself, which can be recovered at any stage of process or from wastes. ${ }^{7}$

Recently, catalyst particles embedded on solid supports have attracted a great deal of interest because of their high surface area and outstanding stability and activity in the liquid phase. ${ }^{8-14}$ The developments concerning the application of polymer supported catalyst in organic synthesis are reviewed with special reference to classical Suzuki,

\footnotetext{
*Author for correspondence (kdinakaran.tvu@gmail.com)
}

Sonogashira and Heck coupling reaction by Kann. ${ }^{15}$ The nanosized Pd particles anchored on inorganic supports such as titnia ${ }^{16}$ and silica ${ }^{17}$ particles are found to be good catalyst for Suzuki ${ }^{18}$ and $\mathrm{Heck}^{19}$ coupling reaction, because their large surface-to-volume ratio endows them with excellent catalytic activity. In particular, nanometre-sized catalyst supports such as nanotubes (NTs) have been selected for highly efficient catalysis because they provide different contact areas and choices of functionalization. ${ }^{17}$ However, the complicated method of functionalization and its control on surface coverage remains as major limiting factors to practical applications. Therefore, it is still important to develop a reliable synthetic route to highly efficient reusable catalysts. Herein, we report a facile method of fabrication of $\mathrm{Pd}$ nanocatalyst-deposited PPZ NTs.

\section{Experimental}

\subsection{Materials}

Hexachlorocyclotriphosphazene (HCCP) and 4,4'-dihydroxydiphenylsulphone (BPS) was purchased from Sigma Aldrich and used without further purification. Triethylamine (TEA) was purchased from Sisco Research Laboratories, India, and used without further purification.

\subsection{Synthesis of $P P Z$}

The synthesis process of the polyphosphazene (PPZ) NTs was similar to that reported previously. ${ }^{20}$ Briefly, BPS (2.300 g, 
$9.1 \mathrm{mmol})$ and HCCP $(0.800 \mathrm{~g}, 2.3 \mathrm{mmol})$ were added to 80 $\mathrm{ml}$ of tetrahydrofuran (THF) followed by $2 \mathrm{ml}$ of TEA. The reaction mixtures were stirred in an ultrasonic bath $(100 \mathrm{~W}$, $80 \mathrm{kHz}$ ) at room temperature for $48 \mathrm{~h}$. The resultant particles were obtained by centrifugation and then were washed three times by using THF and de-ionized water. The obtained solid was dried under vacuum to yield phosphazene NTs as white powders. Yield: $85 \%$.

\subsection{Preparation of $P d-P P Z$}

The PPZ (0.15 g) and Pd acetate $(0.0075 \mathrm{~g}, 0.03 \mathrm{mmol})$ were dispersed in $15 \mathrm{ml}$ of ethanol and kept in ultrasonic bath for 8 h..$^{21,22}$ The product obtained was centrifuged followed by washing with ethanol and then dried at $60^{\circ} \mathrm{C}$. The resulting product containing $0.03 \mathrm{mmol} \mathrm{Pd}$ was designated as PPZ-Pd0.03 and $0.06 \mathrm{mmol} \mathrm{Pd}$ containing catalyst as PPZ-Pd0.06.

\subsection{Aryl coupling reactions}

The phenylboronic acid $(0.200 \mathrm{~g}, 1.600 \mathrm{mmol})$, 4bromoacetophenone $(0.330 \mathrm{~g}, 1.6 \mathrm{mmol}), \mathrm{K}_{2} \mathrm{CO}_{3}(0.680 \mathrm{~g}$, $4.9 \mathrm{mmol})$, PPZ-Pd 0.03 (0.037 g) and THF were taken in round bottom flask fitted with water condenser. The reaction was carried out at $60^{\circ} \mathrm{C}$ in an oil bath for about $48 \mathrm{~h}$. The progress of the reaction was monitored using TLC with $2 \%$ ethyl acetate in n-hexane at ambient temperature. The product obtained was dried and yield was calculated. The second set of reaction was carried out using 4-bromoanisole instead of 4-bromoacetophenone. The Suzuki coupling reaction was experimented with PPZ NT containing 0.06 and $0.03 \mathrm{mmol}$ Pd nanoparticles as catalyst, separately. The Heck coupling reaction was performed using styrene and bromobenzene at $1: 1$ molar ratio and the reaction was maintained at $100^{\circ} \mathrm{C}$ for $48 \mathrm{~h}$.

\section{Results and Discussion}

Scheme 1 illustrates the procedure used for preparing PPZ NTs. Polymerization between HCCP and BPS was carried out in the presence of TEA, an acid acceptor, and THF as solvent. The NTs were successfully prepared under ultrasonic irradiation at room temperature for $48 \mathrm{~h}$. The solid was dried under vacuum to yield phosphazene containing nanoor micro-materials directly as white powders, yield $85 \%$. The PPZ NTs were decorated with Pd nanoparticle by the ethanolic reduction of $\mathrm{Pd}$ acetate. Taking into account the porosity and solution properties of PPZ, we tried to synthesize Pd nanocrystals ex situ throughout the polymer network. $\mathrm{Pd}(\mathrm{OAc})_{2}$ in ethanol was mixed with $\mathrm{PPZ}$ in order to obtain $\mathrm{Pd}(0)$ decorated PPZ, the reaction was allowed to proceed for $8 \mathrm{~h}$ at room temperature. The $\mathrm{Pd}$ acetate is reduced to $\mathrm{Pd}(0)$ by ethanol and the nanocrystals of Pd have been deposited on the PPZ nanotube. The solution turned black as the reaction progressed, the product was filtered and dried.

Figure 1 shows representative transmission electron microscope (TEM) images of the as-prepared PPZ-Pd NTs. The nanotube with a diameter of $120 \mathrm{~nm}$ continuously deposited $\mathrm{Pd}$ nanoparticle with a particle size of $40 \mathrm{~nm}$, which is clearly seen from TEM images. The morphology of PPZ NTs were examined using TEM. TEM studies help to determine the size of the PPZ NTs. TEM image shows that the PPZ nanofibre has the diameter of $120 \mathrm{~nm}$ and has tubular structure.

The XRD pattern of the PPZ-supported Pd catalyst is shown in figure 2 . The nanosturucted materials display three well-resolved diffraction peaks at $2 \theta$ of $40.0^{\circ}, 46.4^{\circ}$ and $68.0^{\circ}$ corresponding to the diffraction of the (111), (200) and (220) lattice planes of the face-centered cubic crystalline structure of the Pd nanoparticles ${ }^{23}$ on PPZ nanotube. In addition, the broad diffraction peak at $2 \theta$ ranging from $5^{\circ}$ to $35^{\circ}$ indicates the presence of polymeric amorphous structure.

\subsection{Suzuki coupling reaction}

In order to explore the synergistic properties that such nanohybrid catalytic system may possess, the catalytic efficiency towards Suzuki coupling reaction was carried out, as depicted in scheme 2.

The Pd-PPZ nanostructures were tested as catalysts in the Suzuki coupling reaction of arylboronic acid with aryl halides in the presence of $\mathrm{K}_{2} \mathrm{CO}_{3}$ as base. The as-synthesized

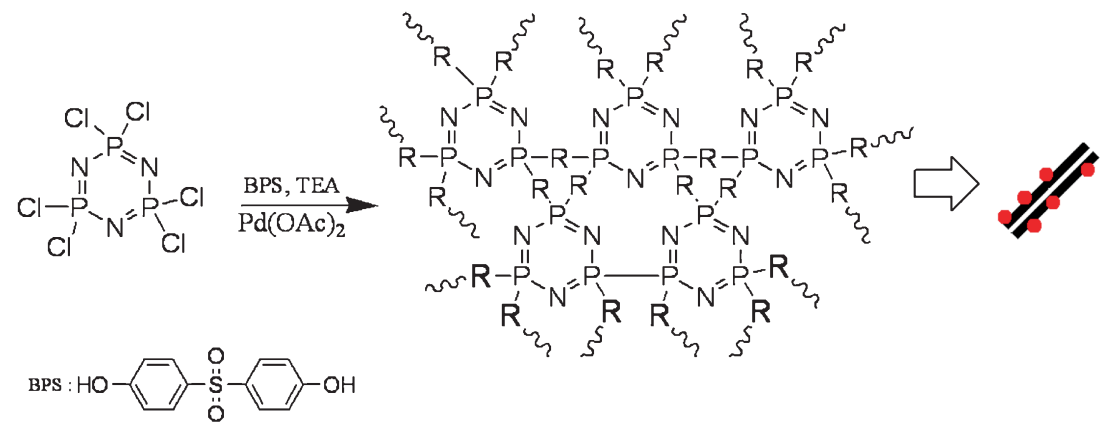

Scheme 1. Preparation of palladium nanoparticle decorated polyphosphazene nanotubes. 

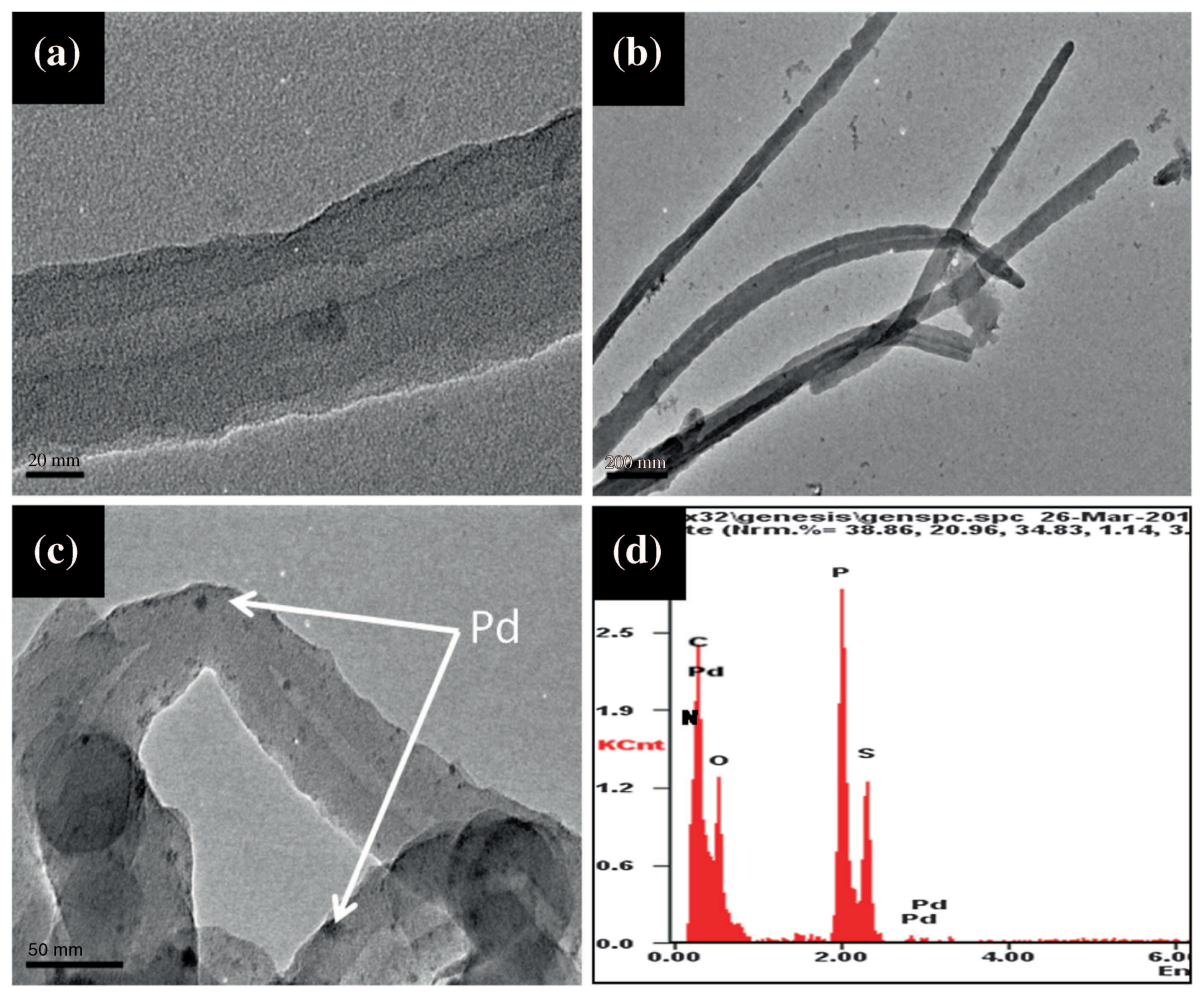

Figure 1. (a and b) HRTEM images of polyphosphazene nanotubes, (c) HRTEM image of Pd decorated polyphosphazene nanotubes and (d) EDX spectra of Pd decorated polyphosphazene nanotubes.

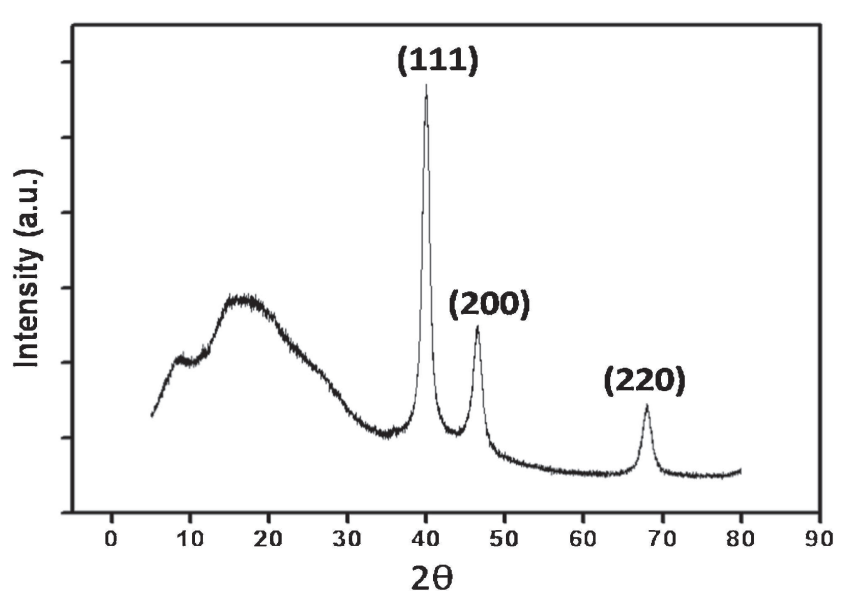

Figure 2. XRD pattern of Pd decorated polyphosphazene nanotubes.

catalyst powder was readily redispersed in polar solvents, even without any stirring, and was amenable to facile centrifugal separation from the reaction solutions. To optimize the overall process, the reaction of 4-bromoacetophenone with phenylboronic acid was selected as a model reaction that could be conveniently carried out at $60^{\circ} \mathrm{C}$. Conversely, high yields of products were obtained in the presence of PPZ-Pd. The Suzuki coupling reaction using PPZ-Pd0.03 catalyst and using $\mathrm{K}_{2} \mathrm{CO}_{3}$ as base gave a yield of $76 \%$. An experiment with PPZ-Pd0.06 nanostructured catalyst gave

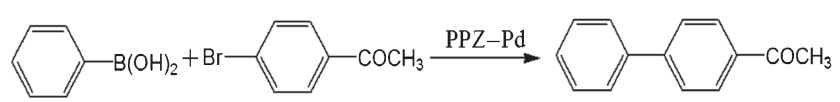

Scheme 2. Suzuki coupling reaction of arylboronic acid and aryl bromide.

$91 \%$ yield. We also note that all of the reactions proceeded smoothly in relatively short times. The heterogeneous PPZ$\mathrm{Pd}$ catalyst shows great advantage in catalysing aryl coupling reaction. The high catalytic performance can be attributed to the hybrid nanotube surface constituted by continuous and interpenetrated phosphazene networks, which provide different contact angle for reagents to approach, large pore size, uniform dispersion of $\mathrm{Pd}$, and relatively small metal particle size. The catalyst was found to be reusable five times without losing its catalytic activity largely. For instance, the yields of Suzuki coupling reaction on successive cycles for the catalyst PPZ-Pd0.06 are 90, 87, 86 and 84\% (table 1).

The Heck coupling reaction using the PPZ-Pd catalyst yields similar results. The reusability of PPZ-Pd catalyst was tested for Suzuki coupling reaction of arylboronic acid and aryl bromide following the same reaction conditions as described above using the recovered catalyst. Each time, after the completion of reaction, the catalyst was recovered by centrifugation and then washed thoroughly with ethanol followed by water to remove the base present in the used catalyst. The recovered catalyst was dried under vacuum at $60^{\circ} \mathrm{C}$ overnight. 
Table 1. Catalytic activity of PPZ-Pd.

\begin{tabular}{lccccc}
\hline Reaction* & $\begin{array}{c}\text { Pd content } \\
\text { (in mmol) }\end{array}$ & $\begin{array}{c}\text { Bromo } \\
\text { compound }\end{array}$ & Base & Solvent & $\begin{array}{c}\text { Yield } \\
(\%)\end{array}$ \\
\hline Suzuki & 0.03 & 4-Bromoacetophenone & $\mathrm{K}_{2} \mathrm{CO}_{3}$ & THF/water & 76 \\
Suzuki & 0.06 & 4-Bromoacetophenone & $\mathrm{K}_{2} \mathrm{CO}_{3}$ & THF/water & 91 \\
Suzuki & 0.06 & 4-Bromoanisole & $\mathrm{K}_{2} \mathrm{CO}_{3}$ & THF/water & 72 \\
Heck & 0.03 & Bromobenzene & $\mathrm{K}_{2} \mathrm{CO}_{3}$ & DMF & 86 \\
Heck & 0.06 & Bromobenzene & $\mathrm{K}_{2} \mathrm{CO}_{3}$ & DMF & 89 \\
\hline
\end{tabular}

*Suzuki coupling reaction of arylboronic acid with aryl halides in the presence of $\mathrm{K}_{2} \mathrm{CO}_{3}$ as base. The reaction was carried out at $60^{\circ} \mathrm{C}$ in an oil bath for about $48 \mathrm{~h}$. Heck coupling reaction was carried out at $100^{\circ} \mathrm{C}$ for $48 \mathrm{~h}$.

\section{Conclusions}

In conclusion, we developed a simple method for preparing recyclable nanostructured supported Pd catalysts and demonstrated their catalytic activities in the carbon-carbon cross-coupling reactions. The catalyst activity is observed to depend on the content of Pd absorbed on the surface of PPZ. The $0.06 \mathrm{mmol}$ of Pd on PPZ catalyst exhibits high activity and corresponding products are obtained with yields of $91 \%$ at $60^{\circ} \mathrm{C}$. TEM images indicate that the nanoparticles are nearly monodisperse in size and stabilized on the surface of PPZ. The catalyst can be readily recovered and reused five times without significant loss of catalytic activity.

\section{Acknowledgements}

K Dinakaran acknowledges the financial support from Department of Science and Technology, India, through Fast Track Young Scientist Scheme: Grant no. SR/FT/CS$103 / 2009$.

\section{References}

1. Negishi E I 2002 In handbook of organopalladium chemistry for organic synthesis; Negishi E, ed. (New York: John Wiley $\&$ Sons)

2. Serov A A and Kwak C 2009 Catal. Commun. 101551

3. Okada T and Kaneko M 2008 Molecular catalysts for energy conversion (Berlin Heidelberg: Springer)

4. Choi K H, Shokouhimehr M, Kang Y S, Chung D Y, Chung Y H, Ahn M and Sung Y E 2013 Bull. Korean Chem. Soc. 34 1195
5. Herrmann W A, Brossmer C, Oefele K, Beller M and Fischer H J 1995 Organomet. Chem. 491 C1

6. Amatore C, Jutand A and M'Barki M A 1992 Organometallics 113009

7. Beletskaya I P and Cheprakov A V 2000 Chem. Rev. 100 3009

8. Lysén M and Köhler K 2006 Synthesis 692

9. Shokouhimehr M, Kim J H and Lee Y S 2006 Synlett 618

10. He H S, Yan J J, Shen R, Zhuo S and Toy P H 2006 Synlett 563

11. Uozumi Y and Kikuchi M 2005 Synlett 1775

12. Crudden C M, Sateesh M and Lewis R 2005 J. Am. Chem. Soc. 12710045

13. Wang Y and Sauer D R 2005 Org. Lett. 62793

14. Motokura K, Fujita N, Mori K, Mizugaki T, Ebitani K and Kaneda K 2005 Tetrahedron Lett. 465507

15. Kann N 2010 Molecules 156306

16. Li Z, Chen J, Su W and Hong M 2010 J. Mol. Catalysis A: Chemical 32893

17. Wan Y, Wang H, Zhao Q, Klingstedt M, Terasaki O and Zhao D 2009 J. Am. Chem. Soc. 1314541

18. Kim N, Kwon M S and Park C M 2004 Park J. Tetrahedron Lett. 457057

19. Wang Z, Xiao P, Shen B and He N 2006 Colloids and Surfaces A: Physicochem. Eng. Aspects 276116

20. Zhu L, Xu Y Y, Yuan W Z, Xi J Y, Huang X B, Tang X Z and Zheng S X 2006 Adv. Mater. 182997

21. Dhas S A and Gedanken A 1998 J. Mater. Chem. 8445

22. Okitsu K, Yue A, Tanabe S and Matsumoto H 2000 Chem. Mater. 123006

23. Du Q and Li Y 2011 Beilstein J. Org. Chem. 7378 